This is an open access article under the terms of the Creative Commons Attribution-NonCommercial-NoDerivs License, which permits use and distribution in any medium, provided the original work is properly cited, the use is non-commercial and no modifications or adaptations are made.

\title{
Reduction in twin stillbirth following implementation of NICE guidance
}

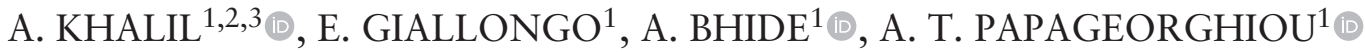 \\ and B. THILAGANATHAN ${ }^{1,2}$ (B) \\ ${ }^{1}$ Fetal Medicine Unit, St George's University Hospitals NHS Foundation Trust, University of London, London, UK; ${ }^{2}$ Vascular Biology \\ Research Centre, Molecular and Clinical Sciences Research Institute, St George's University of London, London, UK; ${ }^{3}$ Twins Trust Centre \\ for Research and Clinical Excellence, St George's Hospital, London, UK
}

KEYWORDS: admission to neonatal intensive care unit; Cesarean section; intrauterine demise; multiple pregnancy; neonatal mortality; NICE guideline; preterm birth; stillbirth; twin

\section{CONTRIBUTION}

What are the novel findings of this work?

Implementation of the NICE twin guideline was associated with $>70 \%$ reduction in the rate of stillbirth in twins without a concomitant increase in neonatal mortality, rate of admission to the neonatal intensive care unit or rate of emergency Cesarean section. The reduction observed in monochorionic twins was higher than that in dichorionic twins.

What are the clinical implications of this work?

Reduction in stillbirth in twins can be achieved through implementation of guidelines. The reduction in stillbirth in twins represents a promising step towards achieving the UK national target of reducing stillbirths by $50 \%$ by 2025. National mortality reports should provide twin data separately for dichorionic and monochorionic pregnancies.

\section{ABSTRACT \\ Objective There has been an unprecedented fall in the rate of stillbirth in twin pregnancy in the UK. It is contested whether implementation of the National Institute for Health and Care Excellence (NICE) guidance on the antenatal management of uncomplicated twin pregnancies has contributed to this change. The aim of this study was to investigate whether the implementation of NICE guidance was associated with a reduction in the rate of stillbirth in twin pregnancies delivered in a large UK hospital.}

Methods This was a retrospective cohort study including all twin pregnancies delivered at St George's Hospital, London, UK, between 2000 and 2018. Data were analyzed according to two time periods: before implementation of the NICE guidance on twins (before June 2013; pre-NICE) and after its implementation (after June 2013; post-NICE). The exclusion criteria were higher-order multiple gestations, pregnancies of unknown chorionicity, pregnancies complicated by miscarriage, those that underwent termination and those diagnosed with vanishing twin. The main outcome was stillbirth. Other outcomes included neonatal death (NND), admission to the neonatal intensive care unit (NICU) and emergency Cesarean section. We planned a priori a sensitivity analysis according to chorionicity. The chi-square test and Mann-Whitney U-test were used to compare outcomes between the study groups.

Results We included in the analysis 1666 twin pregnancies (3332 fetuses), of which 1114 pregnancies (2228 fetuses) were delivered before and 552 pregnancies (1104 fetuses) after June 2013. Of those, 1299 were dichorionic and 354 were monochorionic diamniotic. The incidence of stillbirth was significantly lower in the post-NICE than in the pre-NICE group (3.6 per 1000 births vs 13.5 per 1000 births; $\mathrm{P}=0.008)$. The reduction in stillbirth rate was from 8.5 to 3.6 per 1000 births $(\mathrm{P}=0.161)$ in dichorionic and from 33.6 to 3.8 per 1000 births $(\mathrm{P}=0.011)$ in monochorionic diamniotic twin pregnancies. There was no significant difference in the rates of NND $(\mathrm{P}=0.625)$, NICU admission $(\mathrm{P}=0.506)$ or emergency Cesarean section $(\mathrm{P}=0.820)$ between the two

Correspondence to: Prof. A. Khalil, Fetal Medicine Unit, St George's University Hospitals NHS Foundation Trust, University of London, Blackshaw Road, London, SW17 0QT, UK (e-mail: akhalil@sgul.ac.uk)

Accepted: 6 April 2020 
groups. The median gestational age at delivery was significantly lower in the post-NICE than in the pre-NICE group (median 36.3 vs 36.9 weeks; $\mathrm{P}<0.001$ ), as a consequence of a significant increase in preterm birth between 34 and 37 weeks' gestation (39.3\% vs $27.0 \% ; \mathrm{P}=0.002)$, but not before 34 weeks $(\mathrm{P}=0.473)$.

Conclusions A significant reduction of $>70 \%$ in the stillbirth rate in twin pregnancies was noted after implementation of the NICE guidance. This reduction was statistically significant in monochorionic, but not dichorionic, twin pregnancies. The improvement in twin pregnancy outcome was achieved without a concomitant increase in NND, admission to the NICU or emergency Cesarean section. (C) 2020 The Authors. Ultrasound in Obstetrics \& Gynecology published by John Wiley \& Sons Ltd on behalf of the International Society of Ultrasound in Obstetrics and Gynecology.

\section{INTRODUCTION}

The UK has witnessed an unprecedented fall in the rate of stillbirth in twin pregnancies in recent years ${ }^{1-3}$. According to the Mothers and Babies: Reducing Risk through Audits and Confidential Enquiries across the UK (MBRRACE) 2018 report, the stillbirth rate for twins was almost halved from 11.07 (95\% CI, 9.78-12.47) in 2014 to $6.16\left(95 \%\right.$ CI, 5.20-7.24) per 1000 births in $2016^{1}$. Furthermore, the neonatal mortality rate in twins also fell significantly during this period, from 7.81 (95\% CI, 6.73-9.01) to 5.34 (95\% CI, 4.47-6.36) per 1000 live births ${ }^{1}$. However, it is important to recognize that, despite this significant improvement, the UK stillbirth rate in twins remains higher than that in singleton pregnancies ${ }^{1}$.

One potential contributor to the reduction in stillbirths in the UK is the National Institute for Health and Care Excellence (NICE) guideline on the antenatal care of uncomplicated twin and triplet pregnancies, published in 20114 (Appendix S1) and the related NICE quality standards (QS), published in $2013^{5}$. Key clinical recommendations in this guideline address the dating of twin pregnancies, determining chorionicity and amnionicity, labeling of the fetuses, prenatal screening for aneuploidy, frequency and timing of antenatal visits and ultrasound screening for fetal growth restriction and twin-to-twin transfusion syndrome (TTTS). The recommendations also specify the gestational age for delivery in uncomplicated multiple pregnancies ${ }^{4,5}$. The initial results of the Twin and Multiple Births Association maternity engagement quality improvement initiative suggest that adherence to the NICE-QS is associated with lower rates of stillbirth, neonatal death (NND), emergency Cesarean section and admission to the neonatal intensive care unit $(\mathrm{NICU})^{6}$. The maternity engagement quality improvement initiative, which was funded by the UK Department of Health, aimed at improving outcomes in multiple pregnancies by promoting the implementation of the NICE guideline.

The aim of this study was to investigate whether the implementation of the NICE guidance on the antenatal management of twin pregnancies was associated with a reduction in stillbirth in twin pregnancies delivered in a large UK hospital.

\section{METHODS}

This was a retrospective analysis of data collected prospectively in a single tertiary referral center over a 19-year period from 2000 to 2018. Cases were identified by searching the electronic maternity records, prenatal ultrasound database and neonatal records at St George's Hospital, University of London, UK. In this center, pregnancy and delivery characteristics of all births as well as maternal demographics are routinely recorded prospectively. The inclusion criteria were twin pregnancies delivered at St George's Hospital, and therefore with ascertained pregnancy outcome. The exclusion criteria were higher-order multiple gestations, pregnancies of unknown chorionicity, pregnancies complicated by miscarriage, pregnancies that underwent termination and multiple pregnancies diagnosed with vanishing twin. Gestational age was determined by the crown-rump length of the larger twin at the 11-14-week scan or by head circumference if assessed after 14 weeks' gestation ${ }^{4,7-9}$. Chorionicity was determined by ultrasound evaluation based on the number of placentae and the presence of the lambda or T-sign, and confirmed after birth ${ }^{4,8,9}$. Pregnancies in which data on chorionicity were not available or could not be ascertained were excluded. The ultrasound electronic records were reviewed to ascertain the prenatal diagnosis of monochorionicity-related complications, including TTTS, selective fetal growth restriction (sFGR), twin anemia-polycythemia sequence (TAPS) and twin reversed arterial perfusion sequence.

The main outcome of this study was stillbirth, which was defined as fetal death after 24 weeks' gestation and before birth. We also aimed to investigate the incidence of NND (defined as death of a neonate up to 28 days postpartum), admission to the NICU and emergency Cesarean section. These outcomes were chosen in view of their reported association with the implementation of the NICE-QS6 .

The NICE guidance was published in September 2011 and was subsequently implemented at St George's Hospital during 2012. However, in view of the fact that it takes time to embed clinical guidance in routine clinical practice, and to take into account the length of pregnancy, we decided to compare pregnancy outcomes before and after June 2013, considering the two groups to represent pregnancy care before (pre-NICE) and after (post-NICE) implementation of the NICE guideline. The differences in the monitoring and management protocols between the two study periods are listed in Table S1.

\section{Statistical analysis}

Categorical data are presented as $n(\%)$ and were compared between the two groups using Fisher's exact test or the chi-square test. Continuous data are presented 
as median (interquartile range (IQR)). The D'Agostino and Pearson Omnibus test was used to assess the normality of the data. Non-parametric analysis using the Mann-Whitney $U$-test was then used to compare continuous data between the study groups. We planned a priori a sensitivity analysis according to chorionicity (dichorionic and monochorionic twin pregnancies). The statistical power for each outcome in the entire study population and in the subgroup analysis according to chorionicity is reported. All $P$-values were two-tailed and

Table 1 Characteristics of study population of twin gestations, according to whether they were delivered before or after implementation of National Institute for Health and Care Excellence guideline on antenatal care of twin pregnancy

\begin{tabular}{lccr}
\hline & $\begin{array}{c}\text { Pre- } \\
\text { implementation } \\
(\mathrm{n}=1114)\end{array}$ & $\begin{array}{c}\text { Post- } \\
\text { implementation } \\
(\mathrm{n}=552)\end{array}$ & $\mathrm{P}$ \\
Characteristic & $33(29-36)$ & $34(31-38)$ & $<0.001$ \\
\hline Maternal age (years) & 24.25 & 24.78 & 0.007 \\
BMI $\left(\mathrm{kg} / \mathrm{m}^{2}\right)$ & $(21.70-27.70)$ & $(22.35-28.93)$ & \\
& $116(10.4)$ & $101(18.3)$ & 0.028 \\
BMI $\geq 30 \mathrm{~kg} / \mathrm{m}^{2}$ & $41(3.7)$ & $37(6.7)$ & 0.159 \\
BMI $\geq 35 \mathrm{~kg} / \mathrm{m}^{2}$ & $11(1.0)$ & $9(1.6)$ & 0.637 \\
BMI $\geq 40 \mathrm{~kg} / \mathrm{m}^{2}$ & & & $<0.001$ \\
Ethnicity & $673(60.4)$ & $269(48.7)$ & \\
Caucasian & $182(16.3)$ & $64(11.6)$ & \\
Afro-Caribbean & $131(11.8)$ & $64(11.6)$ & \\
Asian & $24(2.2)$ & $9(1.6)$ & \\
Mixed & $69(6.2)$ & $106(19.2)$ & \\
Other & $35(3.1)$ & $40(7.2)$ & \\
Not recorded & $244(21.9)$ & $15(2.7)$ & $<0.001$ \\
Smoker & $498(44.7)$ & $318(57.6)$ & $<0.001$ \\
Nulliparous & $287(25.8)$ & $171(31.0)$ & 0.025 \\
Assisted conception & $882(79.2)$ & $417(75.5)$ & 0.102 \\
DCDA & $223(20.0)$ & $131(23.7)$ & 0.086 \\
MCDA & $9(0.8)$ & $4(0.7)$ & 1.000 \\
MCMA & &
\end{tabular}

Data are given as median (interquartile range) or $n$ (\%). BMI, body mass index; DA, diamniotic; DC, dichorionic; MA, monoamniotic; $\mathrm{MC}$, monochorionic.
$P<0.05$ was considered statistically significant. Statistical analysis was performed using the statistical software packages SPSS 20.0 (SPSS Inc., Chicago, IL, USA), Stata 11 release 11.2 (College Station, TX, USA) and GraphPad Prism ${ }^{\circledR} 5.0$ for Windows (InStata; GraphPad Software Inc., San Diego, CA, USA).

\section{RESULTS}

\section{Study population}

We included in the analysis 1666 twin pregnancies (3332 fetuses), of which 1114 pregnancies (2228 fetuses) were delivered before June 2013 and 552 pregnancies (1104 fetuses) after June 2013. Of these, 1299 were dichorionic and 367 were monochorionic. There was no significant difference in the proportion of dichorionic and monochorionic twin pregnancies between the two study periods $(P>0.05)$.

The maternal characteristics and pregnancy outcomes of the two study groups are shown in Tables 1 and 2 . Women were significantly older $(P<0.001)$ and more likely to be obese $\left(\mathrm{BMI} \geq 30 \mathrm{~kg} / \mathrm{m}^{2}\right)(P=0.028)$ in the post-NICE than in the pre-NICE group. In the post-NICE group, more women were from ethnic minority backgrounds $(P<0.001)$, were nulliparous $(P<0.001)$ and had conceived via assisted conception $(P=0.025)$ and fewer were smokers $(P<0.001)$ compared with the pre-NICE group (Table 1).

The incidence of stillbirth in the whole study population was 10.2 per 1000 births, while the incidence of NND was 11.5 per 1000 live births. The incidence of stillbirth was higher in monochorionic diamniotic $(22.6$ per 1000 births) than in dichorionic (6.9 per 1000 births) twin pregnancies. The rate of admission to the NICU in the study population was $30.2 \%$, while the incidence of emergency Cesarean section was $28.8 \%$. The median gestational age at delivery was 36.6 weeks (IQR, 34.4-37.4 weeks) and the incidence of preterm birth (PTB) prior to 37 weeks' gestation was $50.7 \%$.

Table 2 Perinatal outcomes of study population of twin gestations, according to whether they were delivered before or after implementation of National Institute for Health and Care Excellence guideline on antenatal care of twin pregnancy

\begin{tabular}{|c|c|c|c|c|}
\hline Outcome & $\begin{array}{c}\text { Pre-implementation } \\
(\mathrm{n}=1114 \text { pregnancies } \\
\mathrm{n}=2228 \text { fetuses) }\end{array}$ & $\begin{array}{l}\text { Post-implementation } \\
\text { (n=552 pregnancies } ; \\
\mathrm{n}=1104 \text { fetuses })\end{array}$ & $\mathrm{P}$ & $\begin{array}{c}\text { Statistical } \\
\text { power } \\
(\%)\end{array}$ \\
\hline Live birth & $2198(98.7)$ & $1100(99.6)$ & 0.008 & 80.5 \\
\hline Stillbirth (per 1000 births) & $30(13.5)$ & $4(3.6)$ & 0.008 & 88.5 \\
\hline Neonatal death (per 1000 live births) & $24(10.9)$ & $14(12.7)$ & 0.625 & 9.0 \\
\hline GA at delivery (weeks) & $36.9(34.6-37.6)$ & $36.3(34.1-37.3)$ & $<0.001$ & $>99.9$ \\
\hline \multicolumn{5}{|l|}{ Preterm birth } \\
\hline$<37$ weeks & $502(45.1)$ & $342(62.0)$ & $<0.001$ & 99.9 \\
\hline 34-37 weeks & $301(27.0)$ & $217(39.3)$ & 0.002 & 99.9 \\
\hline$<34$ weeks & $201(18.0)$ & $125(22.6)$ & 0.473 & 69.1 \\
\hline$<28$ weeks & $57(5.1)$ & $29(5.3)$ & 0.562 & 5.7 \\
\hline Admission to NICU (per 100 live births) & $659(30.0)$ & $338(30.7)$ & 0.506 & 7.9 \\
\hline Emergency Cesarean section & $339(30.4)$ & $141(25.5)$ & 0.820 & 65.3 \\
\hline Birth weight $(\mathrm{g})$ & $2390(1908-2710)$ & $2350(1958-2603)$ & 0.049 & $>99.9$ \\
\hline
\end{tabular}

Data are given as median (interquartile range) or $n(\%)$, unless indicated otherwise. Some percentages are calculated per pregnancy and some per fetus, depending on outcome. GA, gestational age; NICU, neonatal intensive care unit. 


\section{Study outcomes}

There was a significant reduction in the rate of stillbirth from 13.5 per 1000 births before implementation to 3.6 per 1000 births after implementation of the NICE guidelines $(P=0.008)$ (Figure 1, Table 2). There was no significant difference in the rates of NND $(P=0.625)$, NICU admission $(P=0.506)$ or emergency Cesarean section $(P=0.820)$ between the two study periods. The median gestational age at delivery was significantly lower in the post-NICE than in the pre-NICE group $(P<0.001)$. In the post-NICE group, the incidence of PTB prior to 37 weeks $(62.0 \%$ vs $45.1 \% ; P<0.001)$ and between

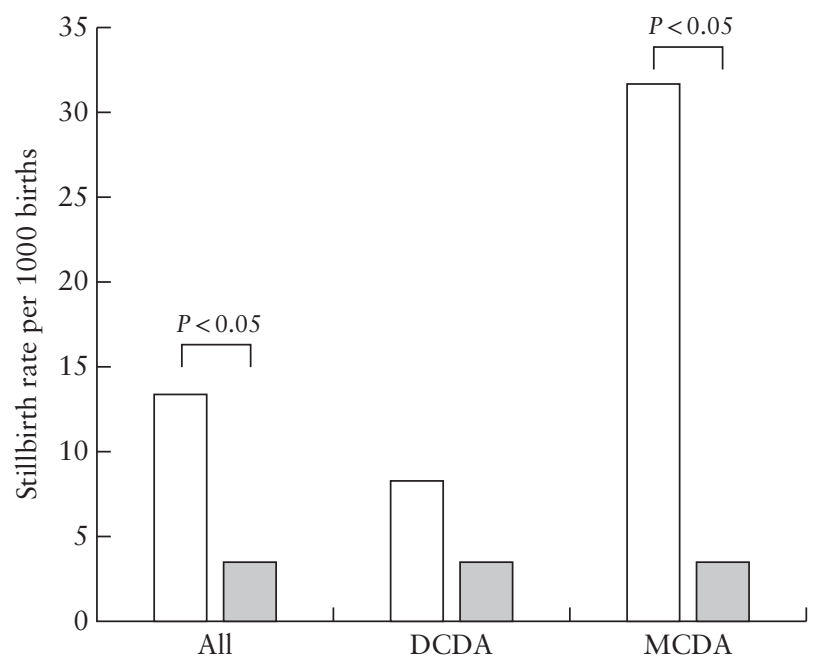

Figure 1 Rate of stillbirth in overall study population and separately in dichorionic diamniotic (DCDA) and monochorionic diamniotic (MCDA) twins, according to whether they were delivered before ( $\square$ ) or after $(\square)$ implementation of National Institute for Health and Care Excellence guideline on antenatal care of twin pregnancy.
34 and 37 weeks $(39.3 \%$ vs $27.0 \% ; P=0.002)$ was significantly higher than in the pre-NICE group. However, PTB prior to 34 weeks' gestation was similar between the two groups $(P=0.473)$ (Table 2$)$.

\section{Subgroup analysis according to chorionicity}

Similar patterns were observed when comparing the outcomes between the two study groups considering separately women with a dichorionic and those with a monochorionic diamniotic twin pregnancy (Table 3). Figure 1 shows the stillbirth rate in dichorionic, as well as monochorionic twin pregnancies (see also Table 3 ).

In dichorionic twin pregnancies, the incidence of stillbirth was lower in the post-NICE than in the pre-NICE group (3.6 per 1000 births vs 8.5 per 1000 births; $P=0.161$ ); however, this difference was not statistically significant (Figure 1, Table 3). The rates of NND $(P=0.568)$, NICU admission $(P=0.406)$, emergency Cesarean section $(P=0.590)$ and incidence of PTB prior to 37 weeks $(P=0.091)$ and between 34 and 37 weeks $(P=0.181)$ was similar between the two groups (Table 3$)$.

In monochorionic diamniotic twin pregnancies the incidence of stillbirth was significantly lower in the post-NICE than in the pre-NICE group (3.8 vs 33.6 per 1000 births; $P=0.011$ ) (Figure 1, Table 3). There was no significant difference in the rates of NND $(P=0.930)$, NICU admission $(P=0.527)$ or emergency Cesarean section $(P=0.577)$ between the two groups. PTB prior to 37 weeks $(96.9 \%$ vs $65.9 \% ; P<0.001)$ and between 34 and 37 weeks $(62.6 \%$ vs $36.8 \% ; P=0.002)$ was significantly higher in the post-NICE than in the pre-NICE group. However, PTB prior to 34 weeks' gestation was similar $(P=0.869)$ between the two groups.

Table 3 Perinatal outcomes of dichorionic diamniotic and monochorionic diamniotic twin pregnancies, according to whether they were delivered before or after implementation of National Institute for Health and Care Excellence guideline on antenatal care of twin pregnancy

\begin{tabular}{|c|c|c|c|c|c|c|c|c|}
\hline \multirow[b]{2}{*}{ Outcome } & \multicolumn{4}{|c|}{ Dichorionic diamniotic twin pregnancies } & \multicolumn{4}{|c|}{ Monochorionic diamniotic twin pregnancies } \\
\hline & $\begin{array}{c}\text { Pre- } \\
\text { implementation } \\
(\mathrm{n}=882 \\
\text { pregnancies; } \\
\mathrm{n}=1764 \text { fetuses })\end{array}$ & $\begin{array}{c}\text { Post- } \\
\text { implementation } \\
(\mathrm{n}=417 \\
\text { pregnancies; } \\
\mathrm{n}=834 \text { fetuses })\end{array}$ & $\mathrm{P}$ & $\begin{array}{c}\text { Statistical } \\
\text { power } \\
(\%)\end{array}$ & $\begin{array}{c}\text { Pre- } \\
\text { implementation } \\
(\mathrm{n}=223 \\
\text { pregnancies; } \\
\mathrm{n}=446 \text { fetuses })\end{array}$ & $\begin{array}{c}\text { Post- } \\
\text { implementation } \\
(\mathrm{n}=131 \\
\text { pregnancies; } \\
\mathrm{n}=262 \text { fetuses })\end{array}$ & $\mathrm{P}$ & $\begin{array}{c}\text { Statistical } \\
\text { power } \\
(\%)\end{array}$ \\
\hline Live birth & $1749(99.1)$ & $831(99.6)$ & 0.161 & 31.3 & $431(96.6)$ & $261(99.6)$ & 0.011 & 87.3 \\
\hline $\begin{array}{l}\text { Stillbirth (per } 1000 \\
\text { births) }\end{array}$ & $15(8.5)$ & $3(3.6)$ & 0.161 & 31.6 & $15(33.6)$ & $1(3.8)$ & 0.011 & 87.5 \\
\hline $\begin{array}{l}\text { Neonatal death (per } \\
1000 \text { live births) }\end{array}$ & $15(8.6)$ & $9(10.8)$ & 0.568 & 7.7 & $9(20.9)$ & $5(19.2)$ & 0.930 & 3.7 \\
\hline \multicolumn{9}{|l|}{ Preterm birth } \\
\hline$<37$ weeks & $355(40.2)$ & $215(51.6)$ & 0.091 & $>99.9$ & 147 (65.9) & 127 (96.9) & $<0.001$ & $>99.9$ \\
\hline $34-37$ weeks & $219(24.8)$ & $135(32.4)$ & 0.181 & 87.1 & $82(36.8)$ & $82(62.6)$ & 0.002 & 99.9 \\
\hline$<34$ weeks & $136(15.4)$ & $80(19.2)$ & 0.553 & 49.3 & $65(29.1)$ & $45(34.4)$ & 0.869 & 39.7 \\
\hline$<28$ weeks & $45(5.1)$ & $21(5.0)$ & 0.543 & 4.3 & $12(5.4)$ & $8(6.1)$ & 0.885 & 7.9 \\
\hline $\begin{array}{l}\text { Admission to NICU } \\
\quad \text { (per } 100 \text { live births) }\end{array}$ & $469(26.8)$ & $234(28.2)$ & 0.406 & 5.1 & $195(45.2)$ & $99(37.9)$ & 0.527 & 57.1 \\
\hline Emergency CS & $262(29.7)$ & $130(31.2)$ & 0.59 & 12.2 & $77(34.5)$ & $41(31.3)$ & 0.577 & 19.6 \\
\hline
\end{tabular}

Data are given as $n(\%)$, unless indicated otherwise. Some percentages are calculated per pregnancy and some per fetus, depending on outcome. CS, Cesarean section; NICU, neonatal intensive care unit. 


\section{DISCUSSION}

\section{Summary of study findings}

Implementation of the NICE guidance was associated with a significant reduction of more than $70 \%$ (from 13.5 to 3.6 per 1000 births) in the stillbirth rate of twin pregnancies. This reduction was greater in monochorionic (about $90 \%$ ) than in dichorionic (about $60 \%$ ) twin pregnancies. Implementation of the NICE guidance was not associated with a significant change in NND, admission to the NICU or emergency Cesarean section, despite an increase in elective delivery at 34-37 weeks' gestation.

\section{Interpretation of findings and comparison with literature}

Our findings support the hypothesis that the reduction in the stillbirth rate in twin pregnancies that has been observed in the UK recently, could, at least in part, be attributed to the implementation of the NICE twin guideline ${ }^{4,5}$. The NICE guidance provided many recommendations (Appendix S1), including the establishment of specialist clinics for twins. Our findings add to the scarce evidence supporting the role of such clinics ${ }^{10,11}$. Women receiving care in a consultant-led multidisciplinary twins clinic at a metropolitan tertiary center in Sydney, Australia, had lower rates of Cesarean section $(55 \%$ vs $70 \%$ ) and PTB at $34-36$ weeks $(26 \%$ vs $44 \%)$ than did those managed in a general antenatal care clinic ${ }^{11}$. It is of note that the incidence of PTB at 34-36 weeks in our study cohort was significantly higher following implementation of the NICE guidance. Despite this, we found no significant increase in rates of NND or NICU admission.

It should be noted that other factors could have contributed to the significant reduction in the stillbirth rate in twin pregnancies, such as implementation of the guideline of the International Society of Ultrasound in Obstetrics and Gynecology on the use of ultrasound in twin pregnancies ${ }^{9}$. The detection of fetal structural abnormalities and aneuploidy has improved. This could have led to early detection of anomalies, allowing termination of the affected twin. Moreover, early detection of monochorionicity-related complications, mainly TTTS and sFGR, could lead to fetal therapeutic interventions with the risk of early fetal loss. The diagnostic criteria of some of the complications affecting twin pregnancies, such as sFGR, have varied over the years. The use of chorionicity-specific twin charts was implemented at St George's Hospital in 2017, which could have altered the assessment of fetal growth in twins $^{12-14}$. Furthermore, routine screening for TAPS, a monochorionic-specific complication associated with an increased risk of perinatal mortality and morbidity ${ }^{15,16}$, was implemented at St George's Hospital in 2012; however, it is unknown whether routine screening is associated with improved pregnancy outcomes ${ }^{17}$.

An important finding of this study is the higher incidence of PTB between 34 and 37 weeks' gestation in the post-NICE than in the pre-NICE group. This probably reflects the implementation of the NICE guidance, which recommends delivery of uncomplicated monochorionic twins by 36 weeks ${ }^{4,5}$. This also explains why PTB between 34 and 37 weeks' gestation was significantly higher in monochorionic, but not dichorionic, twin pregnancies delivered after implementation of the NICE guideline. As stillbirth can occur only during pregnancy, shortening the pregnancy is likely to be responsible for at least some of the reduction in stillbirth. In this regard, it is important that there were no differences in NND between the two study periods.

In the post-NICE compared with the pre-NICE cohort, women were older and more likely to be obese, nulliparous and to have conceived via assisted conception, which is consistent with national demographic changes in the $\mathrm{UK}^{18-21}$. There were more women from ethnic minorities and fewer who smoked in the post-NICE group. With the exception of lower rates of smoking, these factors would have been expected to increase the stillbirth rate, so they cannot explain the decline in the rate in the post-NICE group.

\section{Clinical and research implications}

We have shown significant differences in outcomes for monochorionic and dichorionic twins, and how analyzing them separately makes it possible to gauge the impact of an intervention aimed at twins. It would be very helpful, therefore, if future MBRRACE publications were to report monochorionic and dichorionic twin data separately.

The results of this study and the MBRRACE findings ${ }^{1}$ of a reduction in stillbirths represent promising steps towards achieving the UK national target of reducing stillbirths by $50 \%$ by 2025 . Multiple pregnancies are disproportionately over-represented in stillbirth, neonatal mortality and morbidity ${ }^{22-25}$, and national efforts are needed to address this inequality. We should strive to reduce the rate of stillbirths in multiple pregnancies to levels similar to, or even lower than, that in singletons, which our study and another from The Netherlands have shown is feasible ${ }^{26}$.

\section{Strengths and limitations}

Strengths of our study include the relatively large number of twin pregnancies and ascertainment of outcome data. Furthermore, we reported the data separately in dichorionic and monochorionic twins, overcoming one of the major limitations of the MBRRACE report.

The retrospective design of this study is a limitation inherently associated with a potential risk of bias. However, as we included all twin pregnancies delivering at St George's Hospital, the risk of selection bias is low. The study population included high-risk cases referred for delivery at our tertiary maternity center. This could have led to stillbirth and neonatal mortality rates that are above the average. However, we decided a priori not to perform a sensitivity analysis according to the original planned place of birth. The rationale was that this could potentially artificially reduce the rates of stillbirth and 
neonatal mortality in our study population. Furthermore, it would not be consistent with the current national reporting system, according to which birth data are reported according to the hospital of birth.

In view of the observational nature of the study, it was not possible to prove causation. There might be other contributors to the fall in the rate of stillbirth in twins. However, given that the change in gestational age at delivery coincided with the implementation of the NICE guidance, it is highly likely that it contributed to the fall in the rate of stillbirths. Finally, in view of the long duration of the study, it is impossible to avoid the potential effect of changing practice and improved antenatal care. However, as these changes are not specific to twins, they would be expected to lead to a similar reduction in the rate of stillbirths in both singleton and twin pregnancies. Instead, the overall stillbirth rate in the UK remains one of the highest in Europe, with little significant reduction in the past decades $^{27,28}$.

\section{Conclusions}

Implementation of the NICE guidance was associated with a greater than $70 \%$ reduction in stillbirths in twin pregnancies. This fall was statistically significant in monochorionic, but not in dichorionic, twin pregnancies. Rates of neonatal mortality, NICU admission and emergency Cesarean section remained unchanged. Future studies in other maternity hospitals are needed to prove that these results can be replicated across the UK.

\section{REFERENCES}

1. Draper ES, Gallimore ID, Kurinczuk JJ, Smith PW, Boby T, Smith LK, Manktelow $\mathrm{BN}$, on behalf of the MBRRACE-UK Collaboration. MBRRACE-UK Perinatal Mortality Surveillance Report, UK Perinatal Deaths for Births from January to December 2016. Leicester: The Infant Mortality and Morbidity Studies, Department of Health Sciences, University of Leicester. 2018. https://www.npeu.ox.ac.uk/ downloads/files/mbrrace-uk/reports/MBRRACE-UK\%20Perinatal\%20Surveillance $\% 20$ Full $\% 20$ Report $\% 20$ for $\% 202016 \% 20$ - \%20June $\% 202018$.pdf

2. Khalil A. Unprecedented fall in stillbirth and neonatal death in twins: lessons from the UK. Ultrasound Obstet Gynecol 2019; 53:153-157.

3. Kilby MD, Gibson JL, Ville Y. Falling perinatal mortality in twins in the UK: organisational success or chance? BJOG 2019; 126: 341-347.

4. National Collaborating Center for Women's and Children's Health (UK). Multiple Pregnancy: The Management of Twin and Triplet Pregnancies in the Antenatal Period. NICE Clinical Guidelines, No. 129. RCOG Press: London, 2011.

5. National Institute for Health and Care Excellence. Multiple pregnancy: twin and triplet pregnancies. Ouality Standard. September 2013. https://www.nice.org.uk/ guidance/qs46/resources/multiple-pregnancy-twin-and-triplet-pregnancies-pdf2098670068933

6. NICE works: the final report. Twins and Multiple Births Association Maternity Engagement Project Final Report. https://twinstrust.org/uploads/assets/afcc44b3776e-4341-8a16e9bd990c3425/NICE-works-final-report.pdf
7. Dias T, Mahsud-Dornan S, Thilaganathan B, Papageorghiou A, Bhide A. First-trimester ultrasound dating of twin pregnancy: are singleton charts reliable? BJOG 2010; 117: 979-984.

8. Dias T, Arcangeli T, Bhide A, Mahsud-Dornan S, Papageorghiou A, Thilaganathan B. Second-trimester assessment of gestational age in twins: validation of singleton biometry charts. Ultrasound Obstet Gynecol 2011; 37: 34-37.

9. Khalil A, Rodgers M, Baschat A, Bhide A, Gratacos E, Hecher K, Kilby MD, Lewi L, Nicolaides KH, Oepkes D, Raine-Fenning N, Reed K, Salomon LJ, Sotiriadis A, Thilaganathan B, Ville Y. ISUOG Practice Guidelines: role of ultrasound in twin pregnancy. Ultrasound Obstet Gynecol 2016; 47: 247-263.

10. Newman RB, Ellings JM. Antepartum management of the multiple gestation: the case for specialized care. Semin Perinatol 1995; 19: 387-403.

11. Henry A, Lees N, Bein KJ, Hall B, Lim V, Chen KQ, Welsh AW, Hui L, Shand AW. Pregnancy outcomes before and after institution of a specialised twins clinic: a retrospective cohort study. BMC Pregnancy Childbirth 2015; 15: 217.

12. Stirrup OT, Khalil A, D'Antonio F, Thilaganathan B. Fetal growth reference ranges in twin pregnancy: analysis of the Southwest Thames Obstetric Research Collaborative (STORK) multiple pregnancy cohort. Ultrasound Obstet Gynecol 2015; 45: 301-307.

13. Stirrup OT, Khalil A, D'Antonio F, Thilaganathan B; STORK. Patterns of Secondand Third-Trimester Growth and Discordance in Twin Pregnancy: Analysis of the Southwest Thames Obstetric Research Collaborative (STORK) Multiple Pregnancy Cohort. Fetal Diagn Ther 2017; 41: 100-107.

14. Kalafat E, Sebghati M, Thilaganathan B, Khalil A; Southwest Thames Obstetric Research Collaborative (STORK). Predictive accuracy of Southwest Thames Obstetric Research Collaborative (STORK) chorionicity-specific twin growth charts for stillbirth: a validation study. Ultrasound Obstet Gynecol 2019; 53: 193-199.

15. Lopriore E, Middeldorp JM, Oepkes D, Kanhai HH, Walther FJ, Vandenbussche FP. Twin anemia-polycythemia sequence in two monochorionic twin pairs without oligo-polyhydramnios sequence. Placenta 2007; 28: 47-51.

16. Tollenaar LSA, Slaghekke F, Lewi L, Ville Y, Lanna M, Weingertner A, Ryan G, Arévalo S, Khalil A, Brock CO, Klaritsch P, Hecher K, Gardener G, Bevilacqua E, Kostyukov KV, Bahtiyar MO, Kilby MD, Tiblad E, Oepkes D, Lopriore E and Collaborators. Treatment and outcome of 370 cases with spontaneous or post-laser twin anemia-polycythemia sequence managed in 17 fetal therapy centers. Ultrasound Obstet Gynecol 2020; 56: 378-387.

17. Khalil A, Gordijn S, Ganzevoort W, Thilaganathan B, Johnson A, Baschat A Hecher K, Reed K, Lewi L, Deprest J, Oepkes D, Lopriore E. Consensus diagnostic criteria and monitoring of twin anemia-polycythemia sequence: a Delphi procedure. Ultrasound Obstet Gynecol 2020; 56: 388-394.

18. Human Fertilisation \& Embryology Authority. Fertility Treatment 2014: Trends and Figures. Human Fertilisation \& Embryology Authority: London, 2016.

19. NMPA Project Team. National Maternal and Perinatal Audit: Clinical Report 2017. RCOG Press: London, 2017.

20. Heslehurst N, Lang R, Rankin J, Wilkinson JR, Summerbell CD. Obesity in pregnancy: a study of the impact of maternal obesity on NHS maternity services. BJOG 2007; 114: 334-342.

21. Kanagalingam MG, Forouhi NG, Greer IA, Sattar N. Changes in booking body mass index over a decade: retrospective analysis from a Glasgow Maternity Hospital. BJOG 2005; 112: 1431-1433.

22. Office of National Statistics (ONS) 2016. https://www.ons.gov.uk/ peoplepopulationandcommunity/birthsdeathsandmarriages/livebirths/bulletins/ birthcharacteristicsinenglandandwales/2015\#the-small- rise-in-the-rate- of-womenhaving-multiple-births-has-been-driven-by-those-aged-25-to-29

23. Blondel B, Macfarlane A, Gissler M, Breart G, Zeitlin J; PERISTAT Study Group. Preterm birth and multiple pregnancy in European countries participating in the PERISTAT project. BJOG 2006; 113: 528-535.

24. Mead J. Stillbirth claims. J Patient Safety Risk Management 2010; 16: 77-80.

25. Scheller JM, Nelson KB. Twinning and neurologic morbidity. Am J Dis Child 1992; 146: $1110-1113$.

26. Vasak B, Verhagen JJ, Koenen SV, Koster MP, de Reu PAOM, Franx A, Nijhuis JG, Bonsel GJ, Visser GHA. Lower perinatal mortality in preterm born twins than in singletons: a nationwide study from The Netherlands. Am J Obstet Gynecol 2017; 216: 161.e1-161.e9.

27. Manktelow BM, Smith LK, Evans TA, Hyman-Taylor P, Kurinczuk J, Field D, Smith P, Draper E, on behalf of the MBRRACE-UK collaboration. MBRRACE-UK Perinatal Mortality Surveillance Report - UK Perinatal Deaths for births from January to December 2013. The Infant Mortality and Morbidity Group, Department of Health Sciences, University of Leicester: Leicester, UK, 2015.

28. Flenady V, Koopmans L, Middleton P, Frøen JF, Smith GC, Gibbons K, Coory M, Gordon A, Ellwood D, McIntyre HD, Fretts R, Ezzati M. Major risk factors for stillbirth in high-income countries: a systematic review and meta-analysis. Lancet 2011; 377: 1331-1340.

\section{SUPPORTING INFORMATION ON THE INTERNET}

The following supporting information may be found in the online version of this article:

Appendix S1 Summary of recommendations in National Institute for Health and Care Excellence (NICE) guideline on antenatal management of twin pregnancy (NICE guideline 2011)

Table S1 Change in monitoring and management protocols at St George's Hospital before (pre-NICE) and after (post-NICE) implementation of National Institute for Health and Care Excellence (NICE) guideline on management of twin pregnancies, published in 2011 